\title{
PERANCANGAN MOBILE CATALOGUE KERAJINAN KHAS DAERAH SUMATERA SELATAN
}

\author{
Vivi Sahfitri \\ Dosen Universitas Bina Darma \\ Jalan Jenderal Ahmad Yani No.3 Palembang \\ Sur-el : vivi_sahfitri@binadarma.ac.id
}

\begin{abstract}
South Sumatera is one of the provinces in Indonesia that has its own distinctive characteristic especially in the local handicrafts that become an attraction for tourists who visit this region. South Sumatra consists of several district and city areas that have their own distinctive and cultural characteristics. South Sumatera area is quite spacious with a variety of different tourist attractions in each region, requiring a media information that can reach the community widely and as a medium of tourism promotion in the province of South Sumatera. One of the wealth owned by South Sumatera Province is a variety of typical handicrafts from various regions in South Sumatera. The research resulted in the design of the application catalog typical South Sumatera mobile based Android. Mobile Catalogue Typical Crafts South Sumatera will provide information about the share of South Sumatera handicrafts such as songket, batik, jumputan cloth, blongsong cloth, tanjung cloth, and crafts carving typical Palembang.
\end{abstract}

Keywords: Craft, Specialty, catalog, Mobile

\begin{abstract}
Abstrak : Sumatera Selatan merupakan salah satu Provinsi di Indonesia yang memiliki ciri khas tersendiri terutama pada kerajinan khas daerah yang menjadi daya tarik bagi wisatawan yang berkunjung ke Wilayah ini. Sumatera Selatan terdiri dari beberapa wilayah kabupaten dan kota yang memiliki ciri khas dan budaya masing-masing. Wilayah Sumatera Selatan yang cukup luas dengan berbagai daya tarik wisata yang berbeda disetiap daerah, membutuhkan media informasi yang dapat menjangkau masyarakat secara luas dan sebagai media promosi pariwisata di Provinsi Sumatera Selatan. Salah satu kekayaan yang dimiliki provinsi Sumatera selatan adalah beragam kerajinan khas dari berbagai daerah di Sumatera Selatan. Penelitian menghasilkan Rancangan perangkat lunak katalog kerajinan khas Sumatera Selatan berbasis mobile android. Mobile Catalogue kerajinan khas Sumatera selatan ini akan memberikan informasi tentang berbagi kerajinan Sumatera Selatan seperti songket, batik, kain jumputan, kain blongsong, kain tanjung, dan kerajinan ukiran khas Palembang.
\end{abstract}

Kata kunci: Kerajinan, Khas, Katalog, Mobile

\section{PENDAHULUAN}

Teknologi Informasi dan Komunikasi saat ini telah berkembang dengan pesatnya. Berbagai kemajuan di bidang teknologi Informasi dan komunikasi memberikan berbagai pengaruh bagi kehidupan manusia. Keberadaan Teknologi infomasi membarikan banyak kemudahan dalam menyelesaikan pekerjaan, mempermudah komunikasi serta menyediakan banyak informasi kepada penggunanya. Informasi memiliki pengertian sebabagai proses lebih lanjut dari data yang sudah memiliki nilai tambah, data yang telah diolah menjadi sebuah bentuk yang berarti bagi penerimanya dan bermanfaat bagi pengambilan keputusan saat ini atau saat mendatang [1].

Salah satu produk teknologi informasi yang banyak dimanfaatkan oleh masyarakat secara luas adalah teknologi smartphone. Adanya smartphone telah memberikan banyak kemudahan bagi semua orang, antara lain 
kemudahan berkomunikasi dan kemudahan mencari informasi yang diinginkan. Adanya smartphone yang didukung oleh ketersediaan jaringan internet memberikan banyak kemudahan bagi semua orang dalam membantu pekerjaan mereka[2].

Salah satu manafaat yang dapat diberikan oleh kemajuan teknologi terutama jaringan internet dan teknologi smartphone adalah dengan memanfaatkannya sebagai media untuk melakukan promosi baik barang maupun jasa agar memperoleh jangkauan pasar yang luas untuk dapat dikenal secara lebih luas baik di dalam negeri maupun di luar negeri.

Penelitian ini bertujuan untuk merancang sebuah katalog kerajinan khas Sumatera Selatan berbasis mobile yang berjalan di atas platform android. Sumatera Selatan sendiri merupakan salah satu wilayah provinsi yang ada di Indonesia dengan Ibukota Palembang. Sumatera Selatan memiliki wilayah yang cukup luas, terdiri dari beberapa kabupaten dan kota yang memiliki ciri khas tersendiri khususnya dalam hal Kerajinan tangan daerah. Kerajian memiliki pengertian suatu usaha yang dilakukan secara terus menerus dengan penuh semangat ketekunan, kecekatan, kegigihan, berdedikasi tinggi dan berdaya maju yang luas dalam melakukan suatu karya [3]. Kerajinan tangan dengan karakteristik khas daerah-daerah di Sumatera Selatan merupakan salah satu daya tarik dalam sektor Pariwisata yang dapat menjadi sumber Pendapatan Daerah. Namun, informasi tentang kerajinan tangan khas daerah yang ada di Sumatera Selatan tersebut masih kurang diketahui oleh masyarakat secara luas khususnya para wisatawan yang berkunjung ke daerah-daerah yang ada di Sumatera Selatan.

Salah satu penyebab kurangnya pengetahuan wisatawan bahkan masyarakat Sumatera Selatan sendiri terhadap kerajinan khas yang ada di daerah alaha kurangnya promosi dari Dinas Pariwisata Provinsi serta belum adanya media yang dapat digunakan oleh masyarakat untuk mencari informasi tentang hal tersebut. Perancangan dan pengembangan sebuah perangkat lunak yang dapat memfasilitasi dalam menyebarkan informasi tentang berbagai kerajinan di daerah-daerah di Sumatera Selatan akan sangat membantu sebagai media promosi pariwisata Sumatera Selatan. Perangkat lunak dapat diartikan sebagai metodologi untuk merancang, mengembangkan dengan instruksi langsung komputer untuk melakukan pekerjaan dan dapat ditemukan disetiap aspek kehidupan modern [4]. Perangkat lunak merupakan metodologi, proses, alat, standar, metode organisasi, metode manajemen, sistem jaminan kualitas, dan mengembangkan perangakt lunak skala besar dengan produktivitas yang tinggi, biaya rendah, kulaitas terkontrol, dan pengukuran jadwal pengembangan [5].

Perangkat lunak yang unggul dapat memberikan informasi sesuai dengan kebutuhan penggunanya. Informasi adalah hasil pengolahan sehingga sehingga menjadi bentuk yang pentong bagi penerimanya dan mempunyai kegunaan sebagai dasar dalam pengambilan keputusan yang dapat dirasakan akibatnya secara langsung saat itu juga atau secara tidak langsung pada saat mendatang [6]. Perangkat lunak yang akan dirancang dan dikembangkan dalam penelitian 
ini adalah Katalog Mobile. Katalog merupakan daftar berbagai jenis koleksi perpustakaan yang disusun menurut sistem tertentu [7]. Perangkat lunak akan berjalan diatas platform android sebagai sistem operasinya. Android adalah sistem operasi mobile, termasuk Sistem Operasi middleware dan aplikasi inti [8].

Beberapa penelitian yang menjadi rujukan dalam pembuatan aplikasi salah satunya adalah penelitian yang dilakukan Aldres Pailing dengan judul Katalog Penjualan Rumah Berbasi Android menggunakan Teknologi Augmanted Reality dan Virtual Reality, penelitian ini menghasilkan sebuah katalog yang mampu memproyeksikan objek tiga dimensi rumah sehingga pengguna merasa berada di dalam rumah dan dapat melihat kondisi rumah secara nyata [9]. Penelitian lain dilakukan oleh Arman Suryadi Karim dan zelika Putri Pasha dengan judul E-Katalog Berbasis Mobile pada Perpustakaan Kota Bandar Lampung, penelitian ini menghasilkan sebuah $e$ katalog perpustakaan berbasis Mobile android yang memberikan kemudahan dalam pencarian buku dan booking buku secara online sebelum datang ke perpustakaan [10].

Dengan memanfaatkan perkembangan teknologi informasi melalui penggunaan perangkat lunak katalog kerajinan khas Sumatera Selatan berbasis mobile android dapat menjadi media promosi pariwisata Sumatera Selatan untuk dapat memperkenalkan kerajinan Khas Daerah Sumatera Selatan agar dapat dikenal secara luas dan menjadi objek wisata daerah yang dapat menjadi sumber pendapatan daerah.

\section{METODOLOGI PENELITIAN}

Metode Penelitian dapat diartikan langkah-langak atau cara yang dapat digunakan untuk mencapai tujuan yang dicapai dalam kaitannya dengan pelaksanaan kegiatan penelitian dengan teknik atau alat tertentu. Metode yang digunakan dalam penelitian ini adalah metode Development Research. Metode Development Reseach adalah metode yang digunakan dalam suatu kegiatan penelitian yang bertujuan dan berusaha mengembangkan atau yang sudah ada atau diketahui [11].

\subsection{Metode Pengembangan Sistem}

Metode pengembangan sistem yang diguanal dalam perancangan dan pengembangan katalog mobile kerajinan khas Sumatera Selatan ini adalah metode prototyping. Metode Prototyping merupakan sebuah paradigma baru dalam pengmebangan sistem ddan aplikasi, tidak hanya sekedar suatu evolusi dari metode pengembangan sistem informasi yang sudah ada, tetapi sekaligus merupakan revolusi dalam pengembangan sistem informasi [12]. Tahapan dalam prototyping terdiri dari; 1) Pengumpulan kebutuhan, pada tahap ini Pelanggan dan pengembang bersama-sama mendefiniskan format dan kebutuhan perangkat lunak secara keseluruhan, mengidentifikasikan semua kebutuhan, dan garis besar sistem yang akan dibuat, 2) Membangun prototyping, yang dilakukan pada tahap ini adalah membuat desain sementara yang berpusat pada penyajian kepada pelanggan, misalnya; dengan membuat contoh input dan output, 3) Evaluasi prototyping, jika 
prototype yang sudah dibangun sesuai dengan keinginan pelanggan maka dilakukan evaluasi. JIka sudah sesuai akan dilanjutkan ketahap pengkodean (coding) namun jika belum sesuai maka akan diperbaik dengan mengulang kembali tahap 1,tahap 2 dan tahap 3, 4) Mengkodekan Sistem, tahap ini lakukan jika prototype yang dibuat sudah diterima dan disepakati yang dilanjutkan dengan pengkodean dengan bahasa pemrograman yang sesuai, 5) Menguji Sistem, tahap ini dilakukan untuk mengetahui performance dari sistem yang dibangun. Pengujian sistem dilakukan dengan metode Black Box, 6) Evaluasi Sistem, tahap ini dilakukan untuk mengetahui apakh sistem yang dibangun telah sesuai dengan yang diharapkan. Jika sudah memenuhi dapat dilakukan tahap selanjutnya, namun jika tidak maka perlu dilakukan pengulangan pada tahap 4 dan tahap 5, 7) Menggunakan Sistem, yaitu sistem yang dibangun siap digunakan oleh pelanggan setelah tahap pengujian berhasil dan diterima oleh pelanggan.

\subsection{Metode Pengumpulan Data}

Metode pengumpulan data yang digunakan dalam ini meliputi; 1) Literature Review, atau studi pustaka yang merupakan cara penngumpulan data dengan membaca, mempelajari buku-buku, makalah penelitian atau referensi lain yang berkaitan dengan permasalahan yang dibahas, 2) Observasi, merupakan Teknik Pengamatan yang dilakukan dengan malakukan pengamatan langsung secara teliti dengan mencatat secara sistematis kejadiankejadian, perilaku, objek-objek yang dilihat dan hal-hal lainnya [13], 3) Wawancara, merupakan proses mencari dan memperoleh keterangan untuk tujuan penelitian dengan melakukan tanya jawab sambil bertatap muka antara si penanya dengan si penjawab atau responden. Teknik wawancara yang digunakan pada penelitian ini bertujuan untuk pengumpulan data dengan cara wawancara langsung dengan pihak-pihak yang terkait yang dapat memberikan informasi yang dibutuhkan.

\section{HASIL DAN PEMBAHASAN}

\subsection{Perancangan Sistem}

Perancangan siste dilakukan sebagai langkah awal dalam membangun suatu Perangkat Lunak. Melalui tahap perancangan sistem, dapat diidentifikasikan kebutuhan perangkat lunak dan perangkat keras sistema yang akan dibangun, sehingga sistem yang dihasilkan nantinya dapat sesuai dengan kebutuhan pengguna sebagai bukti tercapainya tujuan dari pembuatan Perangkat Lunak tersebut.

Permodelan sistem yang dilakukan dalam perancangan perangkat lunak katalog mobile Kerajinan khas daerah Sumatera Selatan menggunakan use case diagram. Penggunaan use case diagram memudahkan dalam memberikan penjelasan secara rinci interaksi antara aktor dengan sistem yang dibangun. Gambar 1 menampilkan hubungan antara aktor dengan sistem melalui diagram use Case. 


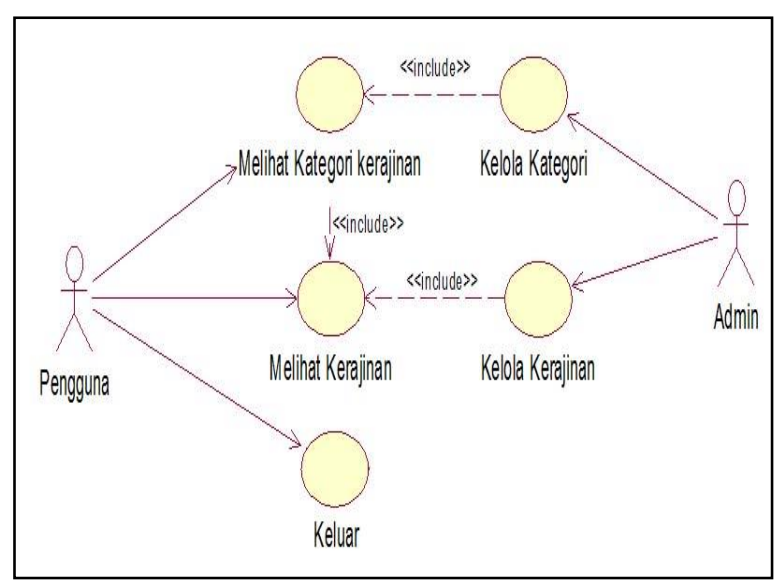

Gambar 1. Usecase Diagram

Setelah merancang use case sebagai tahap analisis interaksi antar actor yang ada dalam sistem, dilanjutkan dengan melakukan analisis fungsional dengan merancang activity Diagram untuk masing-masing aktor yang berinteraksi dengan sistem. Gamba 2 dan gambar 3 menunjukan rancangan activity diagram sistem yang dibangun.

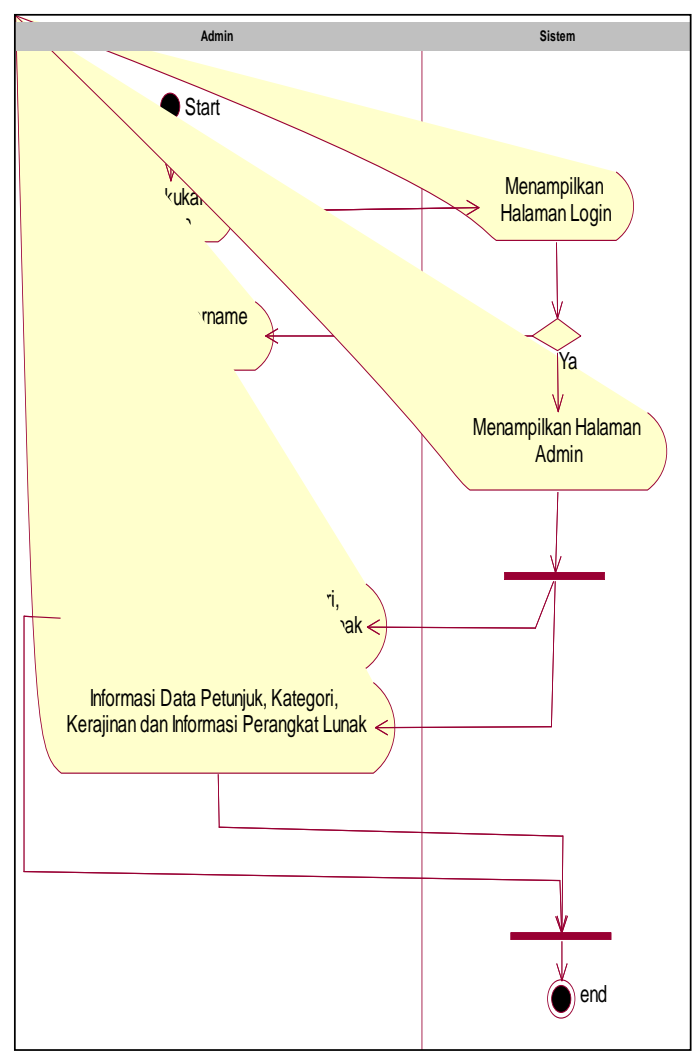

Gambar 2 Activity Admin dan System

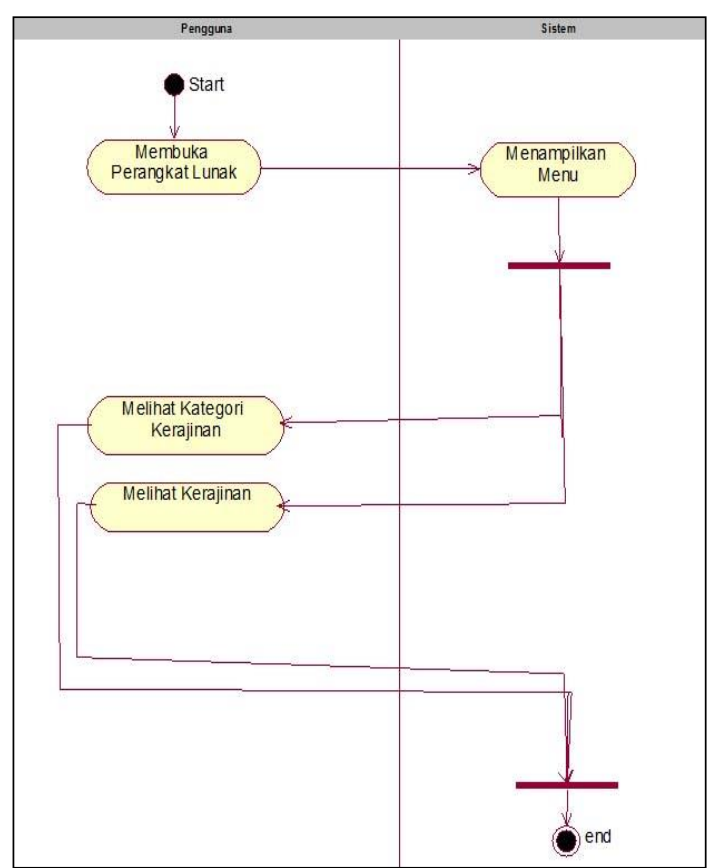

Gambar 3. Activity Pengguna dan System

Untuk mengidentifikasi isi informasi yang akan ditampilkan pada Sistem yang dibangun akan dideskripsikan melalui Class Diagram seperti terlihat pada gambar 4 .

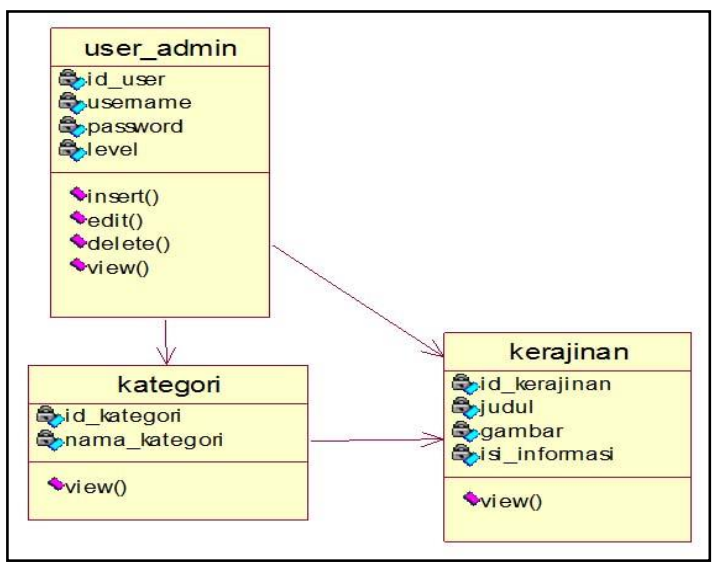

Gambar 4. Class Diagram

\subsection{Interface}

Interface (Antarmuka) merupakan media perantara yang menghubungkan antara sistem dengan pengguna (actor) yang terlibat dalam sistem. Sebelum menjadi antarmuka yang siap 
digunakan, dilakukan perancangan interface yang bertujuan untuk mengakomodasi keinginan pengguna untuk menggunakan sistem yang dibangun. Ada beberapa prinsip yang digunakan dalam merancang atau mendesain antarmuka bagi pengguna (user interface)[14], yaitu User Competibility, Product Competibility, Task Compatibility, Work Flow Compatibility, Consistency and Familiarty, Control, Flexibility and Responsiveness, Invisible Technology, Robustness, Ease of learning. Antar muka (interface) yang dibuat terdiri dari dua bagian yaitu; antarmuka untuk Administrator dan antarmuka untuk Pengguna (user).

\section{A. Menu Administrator.}

Gambar 4,5,6, dan 7 menampilkan menu yang dapat dikelola administrator untuk mengupdate informasi yang berkaitan dengan Perangkat lunak kerajinan khas daerah Sumatera Selatan berbasis mobile android ini.

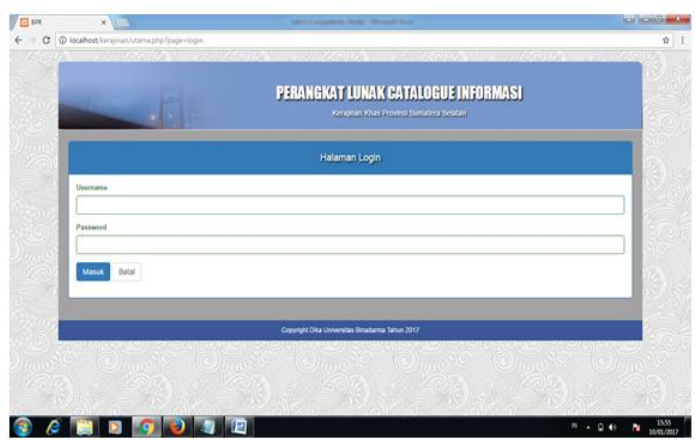

Gambar 4. Halaman login admin

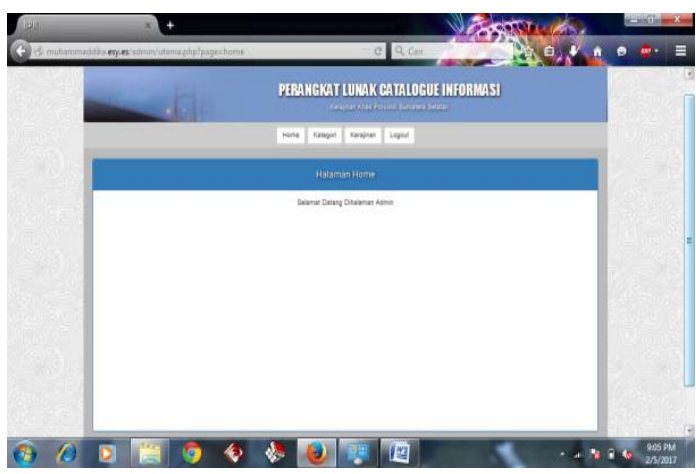

Gambar 5. Halaman admin

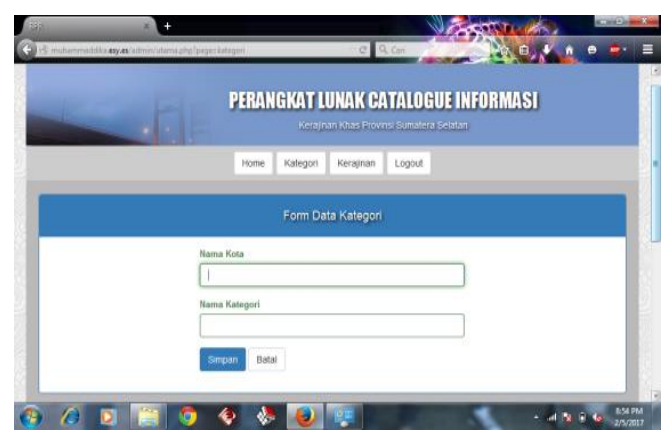

Gambar 6. Halaman admin Data Kategori Kabupaten kota

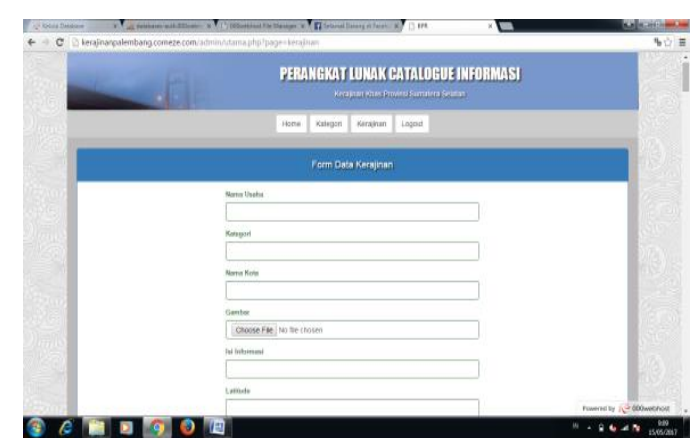

Gambar 7. Halaman Admin Data Kerajinan

B. Menu Pengguna (user)

Menu pengguna merupakan menu yang dapat dimanfaatkan oleh user untuk mencari informasi melalui sistem yang dibangun. Menu pengguna dapat diaakses menggunakan smartphone yang menggunakan platform android. Beberapa tampilan pada halaman pengguna dapat dilihat pada gambar 8,9 , dan 10.

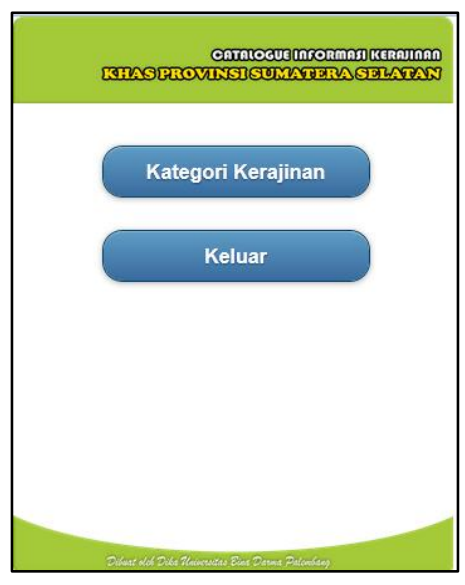

Gambar 8. Halaman index 


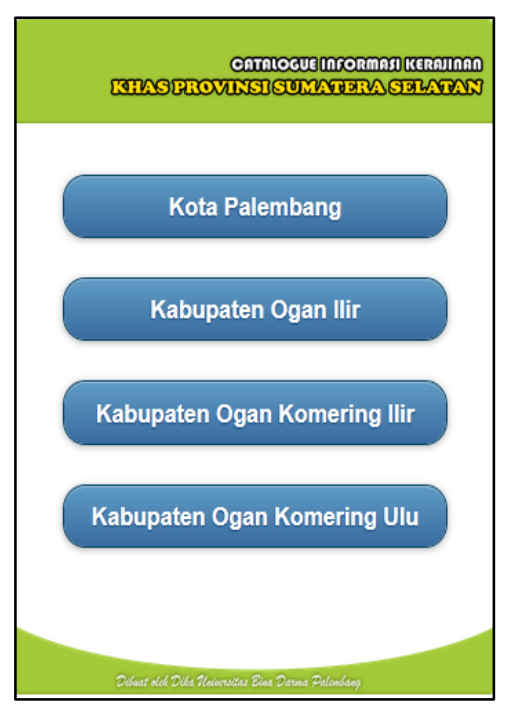

\section{Gambar 9. Halaman Kategori Kabupaten Kota}

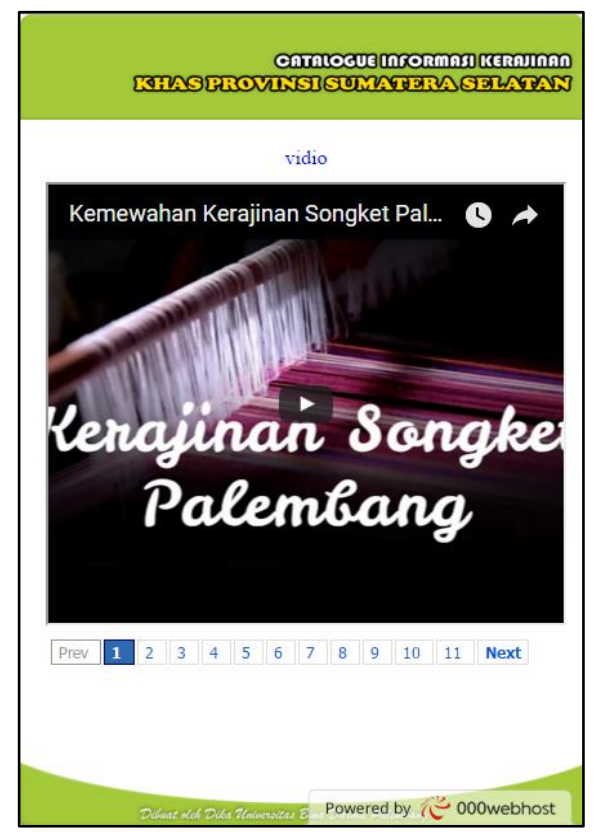

Gambar 10. Contoh Salah Satu Halaman Halaman Jenis Kerajinan (Palembang)

Selain menampilkan Kerajinan - kerajinan khas daera- daerah yang ada di Sumatera Selatan, aplikasi ini juga memberikan innformasi tentang peta wilayah daerah dan peta lokasi Kerajinan tersebut busa diperoleh. Gambar 11 dan 12 merupaka salah satu contoh peta yang dapat ditampilkan oleh Perangkat Lunak.

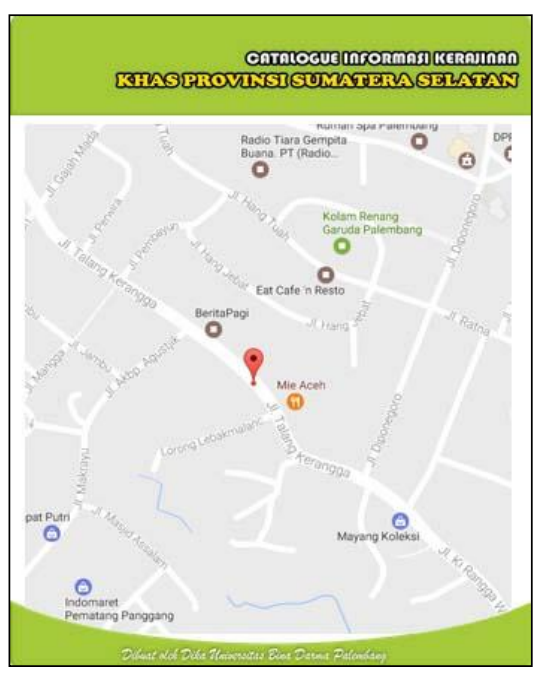

Gambar 11. Halaman Peta Daerah Sumatera Selatan

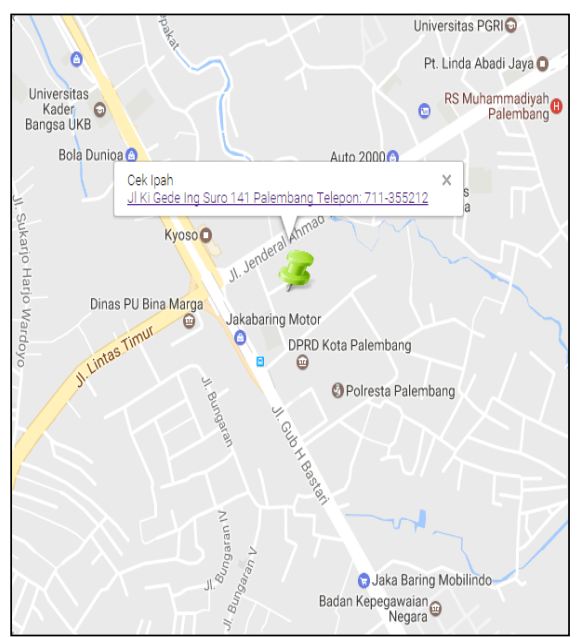

Gambar 11. Contoh salah Satu Halaman Peta Daerah Sumatera Selatan(Palembang)

\section{KESIMPULAN}

Penelitian ini menghasilkan rancangan dan prototype aplikasi Mobile Catalogue kerajinan Khas Derah Sumatera Selatan. Prototype aplikasi yang dibangun dapat dijalankan pada smartphone berplatform Android. Aplikasi dapat memberikan informasi tentang kerajinan khas daerah Sumatera Selatan serta dilengkapi dengan peta yang memberikan informasi lokasi dari kerajinan tersebut. Dengan 
adanya aplikasi berbasis mobile yang memberikan informasi tentang kerajinan khas daerah Sumatera Selatan ini dapat membantu memperkenalkannya secara luas sehingga dapat menjadi daya tarik wisata di Sumatera Selatan. Selain itu aplikasi ini dapat membantu pengunjung atau wisatawan untuk mencari lokasi kerajinan yang mereka inginkan. Prototype yang dibangun dapat dikembangkan kembali menjadi lebih baik dengan informasi yang diberikan lebih banyak dan lebih lengkap serta ddengan tampilan yang lebih menarik.

\section{DAFTAR PUSTAKA}

[1] Sutabri, Tata. 2012. Analisis Sistem Informasi. Andi. Yogyakarta.

[2] Sahfitri,V., Studi Deskriptif Pemanfaatan Fasilitas Hotspot Kampus sebagai Pendukun Proses Pembelajaran, Jurnal JEPIN, Vol.4 No.1, pp. 8-16 Juni 2018.

[3] Pratama. I Putu Agus E, Sistem Informasi dan Implementasinya. Bandung: Informatika, 2014

[4] Simarmata. Janner (2010), Rekayasa Perangkat Lunak, Andi Offset, Yogyakarta.

[5] Mohapatra, P.K.J(2010). Softaware Engineering-A Lifecycle Approach. New Delhi: New Age International Publishers Pvt td.

[6] Sutanta, Edhy. Basis Data dalam Tinjauan Konseptual. Yogyakarta: Andi, 2011.

[7] Fathmi. 2004. Katalogisasi : Bahan ajar diklat calon pustakawan tingkat ahli. Jakarta : Perpustakaan Nasional RI.

[8] Safaat H. 2012 (Edisi Revisi). Pemograman Aplikasi Mobile Smartphone dan Tablet PC Berbasis Android. Informatika. Bandung.

[9] Pailing, Aldres. "Katalog Penjualan Rumah Berbasi Android menggunakan Teknologi Augmanted Reality dan Virtual Reality", Jurnal Teknologi Informasi. Vol. 16 No.1 Universitas Dian Nuswantoro Semarang., pp.35-46, 2017

[10] Karim, Arman Suryadi., Pasha, Zelika Putri. "E-Katalog Berbasis Mobile pada Perpustakaan Kota Bandar Lampung”,
Jurnal Explore. Vol. 8 No. 1 Universitas Bandar Lampung., pp.37-45, 2017.

[11] Supardi. 2005. Metode Penelitian Ekonomi dan Bisnis. Yogyakarta: UII Press

[12] Pressman, R.S. 2010. Software Engineering : a practitioner's approach, McGraw-Hill, New York, 68

[13] Sarwono, Jonathan 2006, Metode Penelitian Kuantitatif dan Kualitatif. Yogyakarta: Graha Ilmu.

[14] W.O Galitz., The essential Guide to Unser Interface Design, Canada: John Wiley \& Sons. 2007 